\title{
Suicide Risk Potential: A Comparison of Psychiatric Patients and Normal Controls in Pakistan
}

\author{
Muhammad Rizwan PhD ${ }^{1 *}$, Razi Sultan Siddiqui ${ }^{2}$ and Lubna Ali PhD ${ }^{1}$ \\ ${ }^{1}$ The Delve Pvt Ltd, Pakistan \\ ${ }^{2}$ The DHA SUFFA University, Pakistan
}

Submission: August 08, 2017; Published: August 31, 2017

*Corresponding author: Muhammad Rizwan, The Delve Pvt Ltd Pakistan; Email: muhammad29psy@yahoo.com

\begin{abstract}
The objective of present study was to investigate difference in the level of suicidal tendencies among patients with psychiatric disorders and normal controls. The sample of present study was consisted of 260 participants including two groups: Clinical group ( $\mathrm{N}=140$ ) and Normal controls $(\mathrm{N}=120)$. The age ranges of participants in both samples were 18-25 years (with the mean age of 22.14 years for clinical group and 21.18 years for normal controls). The clinical group consisted of diagnosed psychiatric patients according to Diagnostic and Statistical Manual of Mental Disorders (DSM IV-TR; American Psychiatric Association, 2000) criterion and were further divided into four sub-groups, including patients of (a) Schizophrenia ( $\mathrm{N}=40$ ); (b) Major Depressive Disorder ( $\mathrm{N}=40$ ); (c) Obsessive Compulsive Disorder ( $\mathrm{N}=40$ ); and (d) Opioid Dependence Disorder ( $\mathrm{N}=20$ ). Research measures employed were: Semi Structured Interview Form of Institute of Clinical Psychology, University of Karachi, and Suicidal Probability Scale (Cull \& Gill, 1982). Descriptive Statistics and One Way Analysis of Variance were employed to analyze the data. Results indicate significant differences among patients with psychiatric disorders and normal controls on the variable of suicidal tendencies $[\mathrm{F}(4,255)=33.579, \mathrm{p}<.05)]$. These findings have implications for clinical interventions and these also suggest avenues for future research.
\end{abstract}

\section{Introduction}

Suicide as a word is of origin in the English Language, derived from the modern Latin suiciduim, which in turn stems from the Latin pronoun for 'self' and verb 'to kill'. American Psychiatric Association [1] has illustrated a number of suiciderelated key terms, such as: suicide that is self imposed death with confirmation that the person intended to die by killing himself; suicidal ideation which comprised on thoughts those are serving as the representative of one's own death; suicidal attempt means the behaviors those are self-injurious with a fatal outcome and accompanied by evidence that the person wants to die; suicidal intend means person's subjective expectation and a desire for a self-destructive act to end their life; deliberate self-harm means willful self-inflicting, painful, destructive, or injurious acts that lacks intent to die. In the current research, the word suicidal tendencies is employed which according to Cull and Gill [2] refers to the suicide risk potential of an individual, based on aggregate of suicidal ideation, hopelessness, negative self-evaluation and hostility.

Psychiatric problems are found to constitute a major risk for suicidal ideation and behaviors Goldston et al. [3]. The high incidence of suicidal behavior in psychiatric disorders is well documented in the literature Beautrais [4]; Bertolote [5]; Meltzer [6]; Shooshtary et al. [7]; Scocco [8]. Numerous studies have documented that suicide is common among several psychiatric illnesses in adults, including major depressive disorder Laukkanen et al. [9]; Slater and Ruth [10], schizophrenia Palmer [11]; Slater and Ruth [10], obsessive compulsive disorder Sareen et al. [12], and substance dependence disorders Cheng [13]. The main objective of the present study is to explore the link between psychiatric disorders and suicidal tendencies by comparing psychiatric patients with normal counterparts.

Suicidal ideation is often associated with depression and is a symptom of major depressive disorder American Psychiatric Association [1]; Carver and Scheier [14]; Feather [15]; Keyes and Lopez [16]; McKelvey [17]. A number of researches have documented this association of suicide with depression. For instance, Jacobson [18] studied the profiles of adolescent psychiatric outpatients and found that those who attempted suicide were more likely to have major depressive disorder. Likewise Laukkanen [9] studied self-image and factors associated 
with suicidal ideation among adolescents seeking psychiatric assessment. Suicidal ideation was reported by $64 \%$ of subjects, of whom $20 \%$ received no psychiatric diagnosis and 58\% had depressive disorders. In addition, the data of young adults support the assumption that suicidal ideations and completed suicide is linked to different specific mental disorders, including major depression Asnis et al. [19]; Zisook [20].

One of the serious complications of psychotic disorders like schizophrenia is the occurrence of suicide attempts Altamura [21]; Ebert [22]; Noll and George [23]; Palmer [11]; Ros and Arranz [24]; Warman [25] and is the major cause of death among individuals with schizophrenia, with as many as 1 out of 4 persons with schizophrenia dying from suicide Conwell et al. [26]. In another view, those suffering with schizophrenia are fifty times more likely to commit suicide that those in the general population Thompson [27]. Higher suicide risk in schizophrenia possibly does not occur in the acute phase and during the hallucinatory phase or active delirium, but in the remission phase when the psychosis is under control Ros and Arran [24].

Moreover, Evren and Evren [28] evaluated the suicide attempt history among schizophrenic patients and compared their socio-demographic and clinical characteristics with schizophrenic patients without a history of suicide attempt. History of suicide attempt was found in $45 \%$ of the patients. The rate of having suicidal ideation, depression, paranoid type schizophrenia and first-degree relatives with psychiatric disorder was high among the group with suicide attempt history. Furthermore, Radomsky [29] evaluated suicidal behavior and its demographic, clinical, and diagnostic correlates among psychiatric patients with psychotic disorders. Results indicated a high rate of suicidal behavior in the group: $30.2 \%$ reported a lifetime history of suicide attempts, and $7.2 \%$ reported a suicide attempt in the month before admission. The highest 1-month and lifetime rates were found in patients with schizoaffective disorder and major depression with psychotic features. Ratings of the lethality of recent suicide attempts were higher for patients with schizophrenia spectrum psychoses (schizophrenia and schizoaffective disorder) than for patients with affective psychoses (major depressive disorder and bipolar disorder). Prevalence rates for recent suicide attempts were highest within the 20-29-years-old group.

In general, patients with anxiety symptoms tend to be more prone to suicidality Feather et al. [15]. However, suicidal behavior in obsessive compulsive disorder is not well documented in the literature and there are few studies have examined suicide behavior in patients with obsessive compulsive disorder. For instance, Sareen et al. [12] conducted a longitudinal study to examine whether anxiety disorders (social phobia, simple phobia, generalized anxiety disorder, panic disorder, agoraphobia, obsessive-compulsive disorder) are independently associated (i.e., after adjusting for comorbid mental disorders) with suicidal ideation and suicide attempts. Their findings indicated that after adjusting for socio-demographic factors and all other mental disorders assessed in the survey, baseline presence of any anxiety disorder was significantly associated with suicidal ideation and suicide attempts in both the crosssectional analysis and longitudinal analysis. Further Zisook [20] in their study found the prevalence of thoughts about death and suicide in all diagnostic groups including anxiety disorders. However, patients with anxiety disorders appeared somewhat less likely than other patients to have tried to kill themselves.

Suicidal behavior is also frequently related with substance abuse or dependence Bukstein et al. [30]; Crumley [31]; Tseng [32]; Asnis et al. [19]. The suicide rate for persons who are heroin dependent is about 20 times more than the rate for the general population Sadock and Sadock [33]. According to our knowledge, there are few studies which have focused suicide behavior in substance dependence disorders generally and opioid dependence disorder particularly. For example: Ialongo [34] and Borges [35] pointed out that major depressive disorders and substance use disorders are among the strongest psychiatric risk factors for suicide thoughts and behavior among youth. Cheng [13] investigated the psychosocial and psychiatric risk factors for suicide and found five important risk factors: loss events; suicidal behavior in first degree relatives; ICD-10 major depressive disorder; emotionally unstable personality disorders; and substance dependence disorder to have independent effects on suicide. Moscicki [36] found that mental and addictive disorders were the most powerful risk factors for suicide in all age groups and related to a greater frequency of suicide attempts, repeat suicide attempts, and more serious ideation.

Lester [37] pointed out that abuse of psychoactive drugs appears to be similarly (though less strongly) associated with a heightened risk of suicide and, in particular, with nonfatal suicidal behaviors. Henriksson et al. [38] investigated the prevalence and comorbidity of mental disorders among a random sample of suicide victims from a nationwide suicide population. The most prevalent disorders were depressive disorders (59\%) and alcohol dependence or abuse (43\%). The prevalence of major depression was higher among females (46\%) than among males (26\%). Alcohol dependence was more common among the males (39\% versus 18\% for females). Other studies have also reported significant relationships of alcohol and drug use with suicidal ideation Annie Arnaud [39]; Yoder [40]. Some other researchers also found high suicide risk among patient with opioid dependence e.g., Krausz [41]; Maremmani et al. [42]; Miotto [43].

Many clinicians have observed that suicidal behavior is a result or complication of severe psychiatric disorders Gill [44]; Jackson [45]; Tseng [32] that's why compared to the general population, patients with psychiatric illnesses have a significantly higher suicide rate Cavanagh et al. [46]; Sadock and Sadock [33]; 
Troister [47]. As empirical evidence Thong [48] identified the risk period and risk factors for suicide in psychiatric patients in Singapore. The most common principal diagnoses were schizophrenia (46.3\%) and major depressive disorder (26.8\%). The other diagnoses were bipolar disorder (6.5\%); adjustment disorder $(4.1 \%)$, delusional disorder $(4.1 \%)$, schizoaffective disorder (2.4\%), brief psychotic disorder (1.6\%) and obsessivecompulsive disorder $(1.6 \%)$. There was greater psychiatric comorbidity in suicidal subjects than control subjects.

According to Tanney [49] depressive disorders; substance abuse disorders; schizophrenia; and, to a less significant degree, personality disorders; anxiety disorders; and eating disorders are widespread among suicide completers than in general population. Likewise Sayar et al. [50] compared suicide attempters with healthy controls on measures of hopelessness, depression, and suicidal ideation. Suicide attempters were more depressed, more hopeless, and displayed greater suicidal ideation than healthy controls. It was also found that depression severity rather than hopelessness correlated with suicidal intent. It was also noticed by Tugcu [51] that mean score and mean subscale scores of depressed group were higher than the normal group on measure of suicide probability.

In addition, a lifetime suicide attempt rate of $20-40 \%$ is found in schizophrenia Amador et al. [52]; Meltzer et al. [6] that is 20 times higher than the reported suicide attempt rate in general population Axelsson et al. [53]; Meltzer et al. [6]; Siris [54]. Similarly, in a 10-year follow up study, the risk for suicide among schizophrenic women was estimated about 18 times greater than that for women in the general population and the suicide risk for schizophrenic men was about 10 times greater than that for men in the general population Caldwell and Gottesman [55]. Another study indicated that suicide risk among patients with anxiety disorders is higher than in the general population Khan [56]. More specifically, in a case report study Maloney [57] examined the prevalence of suicidal behavior and the risk factors associated with such behaviors among an opioid dependent case group and a non-opioid dependent control group. Results indicate that among patients with opioid dependence there is significantly higher lifetime prevalence of suicidal ideation, suicide plans and suicide attempts compared to controls that consists of participants who did not suffer from any mental health disorders.

On the basis of above mentioned literature review it was hypothesized that;

1. There would be a significant difference in the level of suicidal tendencies among patients with psychiatric disorders and normal controls.

\section{Methodology}

\section{Sample}

Young adults with an age range of 18-25 years were the target population of the present study. The sample of this study consisted of 260 participants, including: (1) Clinical Group; and (2) Normal Control Group.

Clinical group consisted of 140 participants, who had been taking treatment for their mental health problems from outpatient clinics of different Psychiatric and Psychological settings with in urban areas of Karachi. They were diagnosed psychiatric patients according to Diagnostic and Statistical Manual of Mental Disorders DSM IV-TR; American Psychiatric Association [1] criteria including patients of (a) Schizophrenia $(\mathrm{N}=40)$; (b) Major Depressive Disorder $(\mathrm{N}=40)$; (c) Obsessive Compulsive Disorder $(\mathrm{N}=40)$; and (d) Opioid Dependence Disorder $(\mathrm{N}=20)$. Participants of Opioid Dependence Disorder group comprised of males only, because of the unavailability of the females with Opioid dependence disorder in outpatient clinical setups of Karachi city.

Normal control group consisted of 120 participants who themselves or their first degree relatives had never experienced any kind of psychological problems that demanded clinical attention or consultancy from any kind of mental health professional. Participants for control group were drawn from different institutions and organizations of Karachi.

The ages of the participants in both samples ranged from 18-25 years with mean age of 22 years for psychiatric patients and 21 years for normal controls. The entire sample belonged to middle socioeconomic class and the minimum education level was Middle (8th Grade). Both the samples (i.e., clinical group and normal controls) were selected on the basis of the following inclusion/exclusion criterion which was pre-determined according to the requirement of the study:

To maintain the homogeneity, only young adults between an age ranges of 18-25 years and with middle socioeconomic status were included in the sample.

Those individuals who also had any chronic medical illness (e.g., cancer, cardiac problem, tuberculosis, etc.) were excluded from both groups i.e., psychiatric patients and normal controls.

Psychiatric patients who appeared to have either co-morbid Axis I or Axis II disorders were also excluded.

\section{Measures}

\section{Semi Structured Interview Form}

Detailed personal and clinical information of both the samples was recorded on the standard Intake form of Institute of Clinical Psychology, University of Karachi, Pakistan. This qualitative measure is designed by the Institute of Clinical Psychology, University of Karachi, based on the criteria of Diagnostic and Statistical Manual for Mental Disorders as well as other details necessary to screen out the diagnosis. It consisted 
of items focusing on an individual's demographic information, presenting problems, history of problem, medical history, family history, educational history, social and occupational history, recreational activities, sexual history, mental state examination, extrasensory perceptions, belief system, affective state, anxieties, gender identity problems, psychosomatic complaints, addiction problems, family psychopathology, personality traits, motivation, and behavior during interview. It is a qualitative measure which usually takes 20- 30 minutes to be administered.

\section{The Suicidal Probability Scale}

The Suicidal Probability Scale (SPS) Cull and Gill [2] is 36-items; self- report screening measure designed to aid in the assessment of suicide risk in adolescents and adults. The major function of the SPS is to provide a global index of suicide risk. Individuals are asked to rate the frequency of their subjective experience and past behaviors using a 4-point Likert scale format ranging from "None or a little of the time" to "Most or all of the time." The responses are then hand scored to evaluate both general and specific suicide risk along several key dimensions. The SPS is a self report measure of suicide risk that can be used as a research instrument to provide quantitative scores. For the present study Udru translation of SPS was used.

\section{Setting}

The scales were individually administered on both samples by the same examiner in order to minimize any change of procedural error in results. An effort was made to assess the whole sample either clinical or control in non-distracting settings, and the order of presentation of tests, and sitting arrangements were made almost identical throughout the study.

\section{Research Procedure}

As reported earlier the sample for the present study comprised of two groups i.e., clinical group and normal controls. Sample for the clinical group was recruited from different psychiatric departments and psychological clinics with in urban areas of Karachi. A letter of consent describing the research project was provided to authorities of selected organization. After getting permission from authorities, the psychiatric patients were approached individually with the help of respective Psychiatrists and Psychologist who had already made a diagnosis of these patients. The first few minutes were spent putting the patients at ease and then the purpose of the study was briefed and discussed in general terms. The researcher assured the confidentiality of the participant's personal information and responses.

The formal consent was taken from patients through Consent Form and only those patients who gave consent to participate were included in the sample. First, the researcher conducted a detailed diagnostic interview and recorded all necessary information about participant's illness on Semi Structured
Interview Form which further confirmed the diagnosis made by the respective psychiatrist/psychologists according to the diagnostic criteria of Diagnostic and Statistical Manual of Mental Disorders DSM-IV-TR; APA [1]. The participants' final diagnosis was determined by a consensus meeting between the researcher, respective psychiatrist/psychologist and an expert clinician's opinion.

After the administration of Semi-Structured Interview Form the Suicidal Probability Scale; Cull and Gill [2]. was administered to assess suicidal tendencies among psychiatric patients as well as normal controls. Participants were allowed to ask questions if they had any difficulty in following instructions and understanding the statements. At the end of the administration of research measures psychiatric patients and concerned authorities were thanked for their cooperation and time. Sample for normal controls was drawn from different institutions and organizations of Karachi. Same procedure, which was applied to clinical group, was followed with these normal controls.

\section{Ethical Issues in Research}

The objective of the entire study, procedures followed, and material used were reviewed and approved by the Board of Advanced Studies and Research (BASR), University of Karachi, Pakistan. Further, this study was conducted with consideration to the privacy and well-being of its participants. Written informed consent was obtained from participants, and they were given the right to withdraw their participation from the study at any time without having to face any consequences. In short, during the process of study, researcher adhered to four key ethical principles: respect for the person's rights and dignity, responsibility, and integrity.

\section{Statistical Analysis}

After scoring, the research data was analyzed to interpret it in statistical terminology. Data was initially compiled into a Microsoft Excel spreadsheet and then analyzed on Statistical Package for Social Sciences (SPSS, V-12.0) software. Descriptive statistics and One Way Analysis Of Variance (ANOVA) was applied to calculate the significance of differences in the level of suicidal tendencies among clinical groups (psychiatric patients with Schizophrenia, Major Depressive Disorder, Obsessive Compulsive Disorder, and Opioid Dependence Disorder) and normal controls. Further, Post hoc Tukey's HSD analysis was conducted to assess the mean difference of scores of various clinical groups that is patients with Schizophrenia, Major Depressive Disorder, Obsessive Compulsive Disorder and Opioid Dependence Disorder and normal controls.

\section{Results}

(Tables 1-4). 


\section{Psychology and Behavioral Science International Journal}

Table 1: Summary of Demographic Characteristics of Clinical Group and Normal Controls.

\begin{tabular}{|c|c|c|c|c|}
\hline \multirow{2}{*}{ Variables } & \multicolumn{2}{|c|}{ Clinical Group } & \multicolumn{2}{|c|}{ Normal Controls } \\
\hline & $\mathbf{N}$ & $\%$ & $\mathbf{N}$ & $\%$ \\
\hline \multicolumn{5}{|l|}{ Gender } \\
\hline Male & 82 & 58.6 & 60 & 50 \\
\hline Female & 58 & 41.4 & 60 & 50 \\
\hline Family Structure & 84 & 60 & 57 & 37.5 \\
\hline $\begin{array}{c}\text { Nuclear } \\
\text { Joint }\end{array}$ & 56 & 40 & 63 & 52.5 \\
\hline Marital Status & 123 & 87.9 & 118 & 98.3 \\
\hline $\begin{array}{c}\text { Single } \\
\text { Married }\end{array}$ & 17 & 12.1 & 2 & 1.7 \\
\hline
\end{tabular}

Table 2: Summary of Demographic Characteristics of Subgroups within Clinical Group.

\begin{tabular}{|c|c|c|c|c|c|c|c|c|}
\hline \multirow[t]{2}{*}{ Variables } & \multicolumn{2}{|c|}{ Schizophrenia } & \multicolumn{2}{|c|}{ MDD } & \multicolumn{2}{|c|}{ OCD } & \multicolumn{2}{|c|}{ ODD } \\
\hline & $\mathbf{N}$ & $\%$ & $\mathbf{N}$ & $\%$ & $\mathbf{N}$ & $\%$ & $\mathbf{N}$ & $\%$ \\
\hline Gender & 21 & 52.5 & 20 & 50 & 19 & 47.5 & 20 & 100 \\
\hline $\begin{array}{c}\text { Male } \\
\text { Female }\end{array}$ & 19 & 47.5 & 20 & 50 & 21 & 52.5 & -- & -- \\
\hline Nuclear & 29 & 72.5 & 21 & 52.5 & 26 & 65.0 & 8 & 38.9 \\
\hline Joint & 11 & 27.5 & 19 & 47.5 & 14 & 35.0 & 12 & 61.1 \\
\hline Marital Status & 39 & 97.5 & 34 & 85.0 & 32 & 80 & 18 & 90 \\
\hline $\begin{array}{c}\text { Single } \\
\text { Married }\end{array}$ & 1 & 2.5 & 6 & 15 & 8 & 20 & 2 & 10 \\
\hline
\end{tabular}

Note: MDD: Major Depressive Disorder; OCD: Obsessive Compulsive Disorder; ODD: Opioid Dependence Disorder

Table 3: Summary of Analysis of Variance for the variable of Suicidal Tendencies among Clinical Groups and Normal Controls ( $N=260)$.

\begin{tabular}{|c|c|c|c|c|c|c|}
\hline & Groups & $\mathbf{M}$ & SD & $\mathbf{F}$ & Sig. & df \\
\hline \multirow{4}{*}{ Clinical Group } & Schizophrenia & 70.2000 & 28.53356 & & & \\
\hline & Major Depressive Disorder & 91.5000 & 23.05734 & & & \\
\hline & Obsessive Compulsive Disorder & 79.4000 & 21.24799 & 33.579 & .000 & 4,255 \\
\hline & Opioid Dependence Disorder & 83.4500 & 29.58569 & & & \\
\hline Normal Controls & & 54.70 & 11.02 & & & \\
\hline
\end{tabular}

Table 4: Post Hoc Tukey's HSD Analysis among Normal Controls and various Clinical Groups for the variable of Suicidal Tendencies.

\begin{tabular}{|c|c|c|c|c|}
\hline & Groups & Mean Difference & Standard Error & Sig \\
\hline \multirow{4}{*}{ Normal Controls } & Schizophrenia & -15.49167 & 3.6412 & .000 \\
\hline & Major Depressive Disorder & -36.79167 & 3.6412 & .000 \\
\hline & Obsessive Compulsive Disorder & -24.69167 & 3.6412 & .000 \\
\hline & Opioid Dependence Disorder & -28.74167 & 4.81147 & .000 \\
\hline \multirow{3}{*}{ Schizophrenia } & Major Depressive Disorder & -21.30000 & 4.45456 & .000 \\
\hline & Obsessive Compulsive Disorder & -9.20000 & 4.45456 & .238 \\
\hline & Opioid Dependence Disorder & -13.25000 & 5.45570 & .111 \\
\hline \multirow{2}{*}{ Major Depressive Disorder } & Obsessive Compulsive Disorder & 12.1000 & 4.45456 & .054 \\
\hline & Opioid Dependence Disorder & 8.05000 & 5.45570 & .579 \\
\hline Obsessive Compulsive Disorder & Opioid Dependence Disorder & -4.05000 & 5.45570 & .946 \\
\hline
\end{tabular}




\section{Psychology and Behavioral Science International Journal}

\section{Discussion}

As we hypothesized that "There would be a significant difference in the level of suicidal tendencies among patients with psychiatric disorders and normal controls". Findings from the present study indicates that psychiatric patients scored significantly higher than normal controls on the variable of suicidal tendencies $[\mathrm{F}(4,255)=33.579, \mathrm{p}<.05$; Table 3$)]$. These findings are consistent with our formulated hypothesis and with previous similar studies (e.g. Cohen and Hart [58]; Gould [59]; Noll [23]; Silverman [60]; Stirling and Hellewell [61]; Sadock and Sadock [33]. Further, to analyze the differences of normal controls from four sub-groups within clinical group and for researcher's interest, additional post hoc Tukey's HSD analysis was conducted Table 4 . All the psychiatric patients i.e., patients of Schizophrenia (MD= -15.491, $\mathrm{p}<.05)$, Major Depressive Disorder $(\mathrm{MD}=36.791, \mathrm{p}<.05)$, Obsessive Compulsive Disorder $(\mathrm{MD}=24.691, \mathrm{p}<.05)$, and Opioid Dependence Disorder $(\mathrm{MD}=$ $28.741, \mathrm{p}<.05$ ), are found to score significantly higher, which indicates high suicidal tendencies in psychiatric patients than normal controls.

Patients with mental illnesses usually face rejection from environment. According to Wahl [61], these people may still find themselves eschewed, stay away from others, and feels as others perceive them less proficient, possibly will have observe themselves being the object of humor, insensitivity, intolerance and may have marginalized against in insurance, in volunteer, and in employment settings. Thus, stigma and discrimination against those with mental illnesses are still considerable problems. Looked in this way, need for or lack of social approval can be one of the reason for high suicidal tendencies in patients with psychiatric disorders compared to normal controls. Social approval is mostly associated with compliance to societal norms and standards. Individuals who have better education, job and life status and who are productive and are economically supportive to their families are usually preferred and get high social approval.

Thus, being diagnosed as having psychiatric disorder can have paralyzed effects on patient's life. Patients with psychiatric disorders start perceiving that due to their illnesses they can never meet the societal expectations and also can never achieve their desired goals and can never get social approval. Consequently, perceived inability to reach desired goals and get social approval induces a sense of hopelessness and despair about future and loss of general control. As Thobaben and Kozlak [62] illustrated that suicidal behavior usually lead by some psychological factors including anger, impulsivity, hopelessness, hostility, isolation, and due to fear or some time denial show resistance towards treatment. Thus, this sense of hopelessness and general loss of control induces in psychiatric patients the feeling that they cannot contribute to the society in a way as others do therefore, their lives have no meanings. In this state of despair and hopelessness, the risk for suicide becomes increased. Tarrier et al. [63] reported that there is direct and independent association of suicide risk with duration of illness and hopelessness.

Another reason for high suicidal tendencies in patients with psychiatric disorders as compared to normal controls is the consequences of their illness and also the perception of the agony of their illness as prolonged and threatening. It has been suggested that suicide attempts of psychiatric patients may be related to the severity, type, and chronicity of their psychopathology Joiner et al. [64]; Minnix [65]; Tseng [32] posited that suicidal behavior may occur as a complication of severe psychiatric disorders, a secondary reaction towards stigmatized mental disorders that are chronic or untreatable. Mann [66] also described suicide as a complication of psychiatric disorders, and extended that psychiatric disorder may cause discord in marital relations as well as in other relations and attainment of poor socio-economic status. The usual outcome of Psychiatric illness is psychosocial adversity, and combination of these both factors cause serious distress in person's life and by this means potentially augment the threat of self harm. Vilhjalmsson [67] indicated that negative economic and domestic events and ongoing difficulties are sometimes overtaxing and debasing which leads to thoughts of suicide. Pompili [68] put forward that insight and awareness of illness make patients realize the medical and social consequences of the disease, that develops in them hopelessness and despair which consequently increases the risk of suicide. Skodlar [69] found that complaints of solitude in patients with suicidal ideation are mainly due to poor communication and interaction abilities, fear of appearing stupid; they don't understand the simple rules of connectedness and feelings of inadequacy to contribute in regular activities with other fellows. They experienced blockage of thoughts when someone is in front of them, they are preoccupied with their appearance, and lack of any clue how to initiate or continue relationships with others. The burden and stress of these disabilities make them vulnerable to think about or even designed and execute the suicide plane. Thus, psychiatric patients perceive that their illness and its consequences will be enduring; therefore in order to get escape from the agony of mental illness, patients with psychiatric disorders think that ending one's life is the only option to escape. They feel that by doing this they will get a permanent solution from their symptoms and the debilitating effects of their illnesses. This could be further illustrated by what Fournier [70] stated that most people do not want to die through suicide, but rather wish to escape from a stressful pain and suffering that seems intolerable and unmanageable. Thus, suicide is a powerful attempt to express the powerlessness of a stressful life situation, and a desperate attempt to seek meaning, purpose, and belonging in life [71,72].

On the basis of findings from this study we can conclude that having a psychiatric illness seriously provoke the risk potential of suicide. We can suggest that mental health professionals 
seriously need to work on suicidal risk potential when dealing with psychiatric patients. The findings of this study offer important suggestions to mental health professionals, health agencies, community caretakers, and NGOs, etc. There are certain limitations of this research. One of the limitations is the limited power of generalizeabilty of the findings due the reasons, such as: Sample with restricted age range i.e., young adults also referred to as youth population with an age range of 18-25 years is selected and inclusion of only four diagnostic groups (e.g. Major depression, schizophrenia, obsessive compulsive disorder and opioid dependence disorder). Therefore, caution should be taken while generalizing the findings to psychiatric patients with age range and psychiatric disorders other than these included in our sample. Moreover, the use of self-report measures to assess suicidal risk is also one of the limitations. Future researches should utilize samples of varied age groups and of patients from different diagnostic categories. Also, future research should focus on gender and socioeconomic status effects while working on the same variables.

\section{Reference}

1. (2000) American Psychiatric Association 2000 Diagnostic and statistical manual of mental disorders ( $4^{\text {th }}$ edn) Washington, USA.

2. Cull J, Gill W (1982) Suicide probability scale (SPS) manual. Western Psychological Services, Los Angeles, California, USA.

3. Goldston DB, Daniel SS, Erkanli A, Reboussin BA, Mayfield A, et al. (2009) Psychiatric diagnoses as contemporaneous risk factors for suicide attempts among adolescents and young adults: Developmental changes. Journal of consulting and clinical psychology 77(2): 281-290.

4. Beautrais AL, Joyce PR, Mulder RT (1996) Risk factors for serious suicide attempts among youth aged 13 through 24 years. Journal of the American academy of child adolescent psychiatry 35(9): 1174-1182.

5. Bertolote JM, Fleischmann A, De Leo D, Wassermann D (2003) Suicide and mental disorders: Do we know enough? British Journal of Psychiatry 183: 382-383.

6. Meltzer HY, Anad R, Alphs L (2000) Reducing suicide risk in schizophrenia: Focus on the role of clozapine. CNS drugs 14(5): 355365.

7. Shooshtary MH, Malakouti SK, Bolhari J, Nojomi M, Poshtmashhadi M, et al. (2008) Community study of suicidal behaviors and risk factors among Iranian adults. Archives of suicide research 12(2): 141-147.

8. Scocco P, Toffol E, Pilotto E, Pertile R, Pavan L (2009) How the psychiatrists of a mental health department managed their patients before an attempted suicide. Psychiatry and clinical neurosciences 63: 706-714.

9. Laukkanen E, Honkalampi K, Hintikka J, Hintikka U, Lehtonen J (2005) Suicidal ideation among help-seeking adolescents: Association with a negative self-Image. Archives of suicide research 9(1): 45-55.

10. Slater E, Ruth M (2001) Clinical psychiatry, ( $3^{\text {rd }}$ ed). Bailliere Tindall, London.

11. Palmer BA, Pankratz VS, Bostwick JM (2005) The lifetime risk of suicide in schizophrenia: A reexamination. Archives of General Psychiatry 62(3): 247-253.

12. Sareen J, Cox BJ, Afifi TO, de Graaf R, Asmundson GJ, ten Have M, et al. (2005). Anxiety disorders and risk for suicidal ideation and suicide attempts: a population-based longitudinal study of adults. Archives of General Psychiatry, 62(11): 1249-1257.

13. Cheng AT, Chen THH, Chen CC, Jenkins R (2000) Psychosocial and psychiatric risk factors for suicide: Case-control psychological autopsy study. British journal of psychiatry 177: 360-365.

14. Carver CS, Scheier MF (2002) Optimism. In CR Snyder, SJ Lopez (Eds.), Hand book of positive psychology. Oxford University Press, New York, USA, pp. 231-243.

15. Feather LJ, Spraggins J, Helsley JD (2008) Anxiety disorders and comorbidities. In JR Vanin, JD Helsley (Eds.), Anxiety disorders: A pocket guide for primary care. Humana Press, New Jersey, USA, pp. 1-211.

16. Keyes CLM, Lopez SJ (2002) Toward a science of mental health: positive directions in diagnosis and interventions. In CR Snyder, SJ Lopez (Eds.), Handbook of positive psychology. NY: Oxford University Press, USA, p. 45-59.

17. McKelvey RS, Davies LC, Pfaff JJ, Acres J, Edwards S (1998) Psychological distress and suicidal ideation among 15-24-year-olds presenting to general practice: a pilot study. Australian and New Zealand journal of psychiatry 32(3): 344-348.

18. Jacobson CM, Muehlenkamp JJ, Miller AL, Turner JB (2008) Psychiatric impairment among adolescents engaging in different types of deliberate self-harm. Journal of clinical child \& adolescent psychology 37(2): 363-375.

19. Asnis GM, Friedman TA, Sanderson WC, Kaplan ML, van Praag HM, et al. (1993) Suicidal behaviors in adult psychiatric outpatients, I: description and prevalence. The American journal of psychiatry 150(1): 108-112.

20.Zisook S, Goff A, Sledge P, Shuchter SR (1994) Reported Suicidal Behavior and Current Suicidal Ideation in a Psychiatric Outpatient Clinic. Annals of Clinical Psychiatry 6(1): 27-31.

21. Altamura AC, Bassetti R, Bignotti S, Piolib R, Mundo E (2003) Clinical variables related to suicide attempts in schizophrenic patients: a retrospective study. Schizophrenia research 60(1): 47-55.

22. Ebert MH, Loosen PT, Nurcombe B (2000) Current diagnosis \& treatment in psychiatry. The McGraw-Hill Companies, New York, USA.

23. Noll R (2006) The encyclopedia of schizophrenia and other psychotic disorders ( $3^{\text {rd }}$ edn). Facts on File Inc, New York, USA.

24. Ros S, Arranz FJ (2007) Clinics: Schizophrenia: A Clinical Review. In H Buschmann, JL Díaz, J Holenz, A Párraga, A Torrens, JM Vela (Eds.), Antidepressants, Antipsychotics, Anxiolytics. WILEY-VCH, New York, USA.

25. Warman DM, Forman EM, Henriques GR, Brown GK, Beck AT (2004) Suicidality and psychosis: Beyond depression and hopelessness. Suicide and life-threatening behavior 34(1): 77-86.

26. Conwell Y, Duberstein PR, Cox C, Herrmann JH, Forbes NT, et al. (1996) Relationships of age and axis I diagnosis in victims of completed suicide: A psychological autopsy study. American journal of psychiatry 153(8): 1001-1008.

27. Thompson ML (2007) Mental illness. Greenwood Press, Westport, USA

28. Evren C, Evren B (2004) Characteristics of schizophrenic patients with a history of suicide attempt. International Journal of Psychiatry in Clinical Practice 8(4): 227-234.

29. Radomsky ED, Haas GL, Mann JJ, Sweeney JA (1999) Suicidal behavior in patients with schizophrenia and other psychotic disorders. American journal of psychiatry 156(10): 1590-1595. 
30. Bukstein OG, Brent DB, Perper JA, Mortiz G, Schweers J, et al. (1993) Risk factors for completed suicide among adolescents with a lifetime history of substance abuse: A case control study. Acta psychiatrica Scandinavica 88: 403-408.

31. Crumley FE (1990) Substance abuse and adolescent suicidal behavior The journal of the American medical association 263(22): 3051-3056.

32. Tseng WS (2001) Handbook of cultural psychiatry. Academic press, San Diego, USA.

33. Sadock BJ, Sadock VA (2007) Kaplan \& Sadock's Synopsis of Psychiatry: Behavioral Sciences/Clinical Psychiatry $\left(10^{\text {th }}\right.$ edn). Philadelphia: Lippincott Williams \& Wilkins, Pennsylvania, USA.

34. Ialongo NS, Edelsohn G, Kellam SG (2001) A further look at the prognostic power of young children's reports of depressed mood and feelings. Child Development 72(3): 736-747.

35. Borges G, Walters EE, Kessler RC (2000) Associations of substance use, abuse, and dependence with subsequent suicidal behavior. American journal of epidemiology 151(8): 781-789.

36. Moscicki EK (1997) Identification of suicide risk factors using epidemiologic studies. Psychiatric Clinics of North America 20(3): 499-517.

37. Lester D (1992) Decriminalization of suicide in Canada and suicide rates. Psychological reports 71(3 Pt 1): 738.

38. Henriksson MM, Aro HM, Marttunen MJ, Heikkinen ME, Isometsa ET, et al. (1993) Mental disorders and comorbidity in suicide. The American Journal of Psychiatry 150(6): 935-940.

39. Annie M, Arnaud B, Barbara B (1999) Substance abuse and drugrelated death, suicidal ideation and suicide: A review Crisis: The journal of crisis intervention and suicide prevention 20(1): 28-35.

40. Yoder KA, Whitbeck LB, Hoyt DR, LaFromboise T (2006) Suicidal ideation among American Indian youths. Archives of suicide research 10(2): 177-190.

41. Krausz M, Degkwitz P, Haasen C, Verthein U (1996) Opioid addiction and suicidality. Crisis: The journal of crisis intervention and suicide prevention 17(4): 175-181

42. Maremmani I, Pani PP, Canoniero S, Pacini M, Perugi G, et al. (2007) Is the bipolar spectrum the psychopathological substrate of suicidality in heroin addicts? Psychopathology 40(5): 269-277.

43. Miotto K, McCann MJ, Rawson RA, Frosch D, Ling W (1997) Overdose, suicide attempts and death among a cohort of naltrexone-treated opioid addicts. Drug and alcohol dependence 45(1-2): 131-134.

44. Gill D (2007) Hughes' Outline of Modern Psychiatry, ( $5^{\text {th }}$ edn). John Wiley \& Sons Ltd, London.

45. Jackson HJ, McGorry PD (Eds.), (2009) The Recognition and Management of Early Psychosis: A Preventive Approach (2 ${ }^{\text {nd }}$ edn). Cambridge: Cambridge University Press, USA.

46. Cavanagh JT, Carson AJ, Sharpe M, Lawrie SM (2003) Psychological autopsy studies of suicide: a systematic review. Psychological Medicine 33(3): 395-405.

47. Troister T, Links P, Cutcliffe JR (2008) Review of predictors of suicide within 1 year of discharge from a psychiatric hospital. Current psychiatry reports $10(1)$ : 60-65.

48. Thong JY, Su AC, Chan YH, Chia BH (2008) Suicide in psychiatric patients: case-control study in Singapore. Australian and New Zealand Journal of Psychiatry 42(6): 509-519.

49. Tanney BL (1992) Mental disorders, psychiatric patients, and suicide. In RW Maris, AL Berman, JT Maltsberger, RI Yufit (Eds.), Assessment and Prediction of Suicide. Guilford, New York, USA. pp. 277-320.
50. Sayar K, Kose S, Acar B, Ismail, Reeves RA (2004) Predictors of suicidal behavior in a sample of Turkish suicide attempters. Death studies 28 (2): $137-150$

51. Tugcu H (2006) A study various factors related to suicide probability. Kriz Dergisi 14 (2): 17-21.

52. Amador XF, Friedman JH, Kasapis C, Yale SA, Flaum M, et al. (1996) Suicidal behavior in schizophrenia and its relationship to awareness of illness. The American journal of psychiatry 153(9): 1185-1188.

53. Axelsson R, Lagerkvist-Briggs M (1992) Factors predicting suicide in psychotic patients. European archives of psychiatry and clinical neuroscience 241(5): 259-266.

54. Siris SG (2001) Suicide and schizophrenia. Journal of psychopharmacology 15(2): 127-135.

55. Caldwell CB, Gottesman II (1990) Schizophrenics kill themselves too: A review of risk factors for suicide. Schizophrenia bulletin 16(4): 571589.

56. Khan A, Leventhal RM, Khan S, Brown WA (2002) Suicide risk in patients with anxiety disorders: a meta-analysis of the FDA database. Journal of affective disorders 68 (2-3): 183-190.

57. Maloney E, Degenhardt L, Darke S, Mattick R, Nelson E (2007) The prevalence and associated risk factors of suicidal behavior among opioid dependent persons: a case-control study. Sydney: National Drug and Alcohol Research Centre, University Of New South Wales, Addition 102(12): 1933-1941

58. Cohen RI, Hart JJ (1988) Student psychiatry today: A comprehensive text book. Oxford: Hainemann, USA.

59. Gould MS, Greenberg T, Velting DM, Shaffer D (2003) Youth suicide risk and preventive interventions: A review of the past 10 years. Journal of the American academy of child adolescent psychiatry 42(4): 386-405.

60. Silverman MM (2005) Helping college students cope with suicidal impulses. In RI Yufit, D Lester (Eds.), Assessment, treatment, and prevention of suicidal behavior. John Wiley \& Sons, Inc, New Jersey, USA.

61. Wahl OF (1999) Mental health consumers' experience of stigma Schizophrenia bulletin 25(3): 467-478.

62. Thobaben M, Kozlak JB (2007) The phenomenon of suicide. Home health care management practice 19(4): 313-316.

63. Tarrier N, Barrowclough C, Andrews B, Gregg L (2004) Risk of nonfatal suicide ideation and behavior in recent onset schizophrenia: The influence of clinical, social, self-esteem and demographic factors. Social psychiatry and psychiatric epidemiology 39(11): 927-937.

64. Joiner T Walker RL, Rudd DM, Jobes DA (1999) Scientizing and routinizing the assessment of suicidality in outpatient practice. Professional Psychology, Research and Practice 30: 447-453.

65. Minnix JA, Romero C, Joiner T, Weinberg EF (2007) Change in "resolved plans" and "suicidal ideation" factors of suicidality after participation in an intensive outpatient treatment program. Journal of affective disorders 103(1): 63-68.

66. Mann JJ (2002) A current perspective of suicide and attempted suicide. Annals of internal medicine 136(4): 302-311.

67. Vilhjalmsson R, Sveinbjarnardottir E, Kristjansdottir G (1998) Factors associated with suicide ideation in adults. Social Psychiatry and Psychiatric Epidemiology 33(3): 97-103.

68. Pompili M, Ruberto A, Kotzalidis GD, Girardi P, Tatarelli R (2004) Suicide and awareness of illness in schizophrenia: an overview. Bulletin of the menninger clinic 68(4): 297-318.

69. Skodlar B, Tomori M, Parnas J (2008) Subjective experience and 
suicidal ideation in schizophrenia. Comprehensive psychiatry 49(5): 482-488.

70. Fournier RR (2005) Group therapy and suicide. In RI Yufit, D Lester (Eds.), Assessment, treatment, and prevention of suicidal behavior John Wiley \& Sons, Inc, New Jersey, USA, pp.313-333.
71. Kessler RC, Borges G, Walters EE (1999) Prevalence of and risk factors for lifetime suicide attempts in the national comorbidity survey. Archives of general psychiatry 56(7): 617-626.

72. Stirling JD, Hellewell JSE (1999) Psychopathology. Routledge, London.
This work is licensed under Creative

Commons Attribution 4.0 License

DOI: 10.19080/PBSIJ.2017.06.555685
Your next submission with Juniper Publishers will reach you the below assets

- Quality Editorial service

- Swift Peer Review

- Reprints availability

- E-prints Service

- Manuscript Podcast for convenient understanding

- Global attainment for your research

- Manuscript accessibility in different formats

( Pdf, E-pub, Full Text, Audio)

- Unceasing customer service

Track the below URL for one-step submission https://juniperpublishers.com/online-submission.php 